References

1. Barone JA. Domperidone: a peripherally acting dopamine ${ }_{2}$-receptor antagonist. Ann Pharmacother 1999;33: 429-40.

2. Joss RA, Goldhirsch A, Brunner KW, Galeazzi RL. Sudden death in cancer patient on high-dose domperidone. Lancet 1982;1:1019.

3. Giaccone G, Bertetto O, Calciati A. Two deaths during prophylactic antiemetic treatment with high doses of domperidone and methylprednisolone. Lancet 1984;2:1336-7.

4. Osborne RJ, Slevin ML, Hunter RW,
Hamer J. Cardiotoxicity of intravenous domperidone. Lancet 1985;2: 385.

5. Roussak JB, Carey P, Parry H. Cardiac arrest after treatment with intravenous domperidone. BM7 (Clin Res Ed) $1984 ; 289: 1579$

6. US Food and Drug Administration. FDA warns against women using unapproved drug, domperidone, to increase milk production [FDA Talk Paper]. Rockville (Md): FDA; 2004 June 7. Available: www.fda.gov/bbs /topics/ANSWERS/2004/ANS01292 .html (accessed 2004 Aug 31).
7. Da Silva OP, Knoppert DC, Angelini MM, Forret PA. Effect of domperidone on milk production in mothers of premature newborns: a randomized, double-blind, placebo-controlled trial. CMA7 2001;164(1):17-21.

8. Heykants J, Hendriks R, Meuldermans W, Michiels M, Scheygrond H, Reyntjens $\mathrm{H}$. On the pharmacokinetics of domperidone in animals and man. IV. The pharmacokinetics of intravenous domperidone and its bioavailability in man following intramuscular, oral and rectal administration. Eur 7 Drug Metab Pharmacokinet 1981;6(1):61-70.

IN THE LITERATURE

\title{
Should people with asymptomatic carotid artery stenosis undergo endarterectomy for primary stroke prevention?
}

Halliday A, Mansfield A, Marro J, Peto C, Peto R, Potter J, et al; MRC Asymptomatic Carotid Surgery Trial (ACST) Collaborative Group. Prevention of disabling and fatal strokes by successful carotid endarterectomy in patients without recent neurological symptoms: randomised controlled trial. Lancet 2004;363:1491-502.

Background: Carotid endarterectomy (CE) is well established as a beneficial procedure for reducing the risk of stroke among patients with symptomatic high-grade carotid artery disease. ${ }^{1}$ However, its role in reducing the risk among patients with asymptomatic carotid artery stenosis (i.e., no prior cerebral or retinal transient ischemic attack [TIA] or stroke) has been less certain and the subject of much controversy. ${ }^{2}$

Design: This multicentre randomized trial is the world's largest vascular surgery trial. From 1993 to 2003, it enrolled 3120 asymptomatic patients with carotid artery stenosis $\geq 60 \%$ (on ultrasound). Patients were randomly allocated to either immediate $\mathrm{CE}$ or medical therapy and deferral of $\mathrm{CE}$. Patients with poor surgical risk or a cardiac source of emboli were excluded. Surgeons were re$\vec{\sim}$ quired to have a perioperative risk of stroke or death of $6 \%$ or less. Medical treatment was left to the discretion of the treating physician. The main outcomes were perioperative morbidity and mortality, and the incidence of nonperioperative stroke.
Results: The risk of stroke or death within 30 days of CE was $3.1 \%$. The overall 5 -year risk of stroke (including perioperative stroke) was lower in the immediate surgery group than in the medical therapy group $(6.4 \% \mathrm{v}$. $11.8 \%, p<0.0001$ ), for a relative risk reduction of about $50 \%$. Subgroup analyses showed a statistical benefit in favour of immediate CE for both men and women, but not for patients aged 75 years and older. CE was particularly beneficial in those with elevated cholesterol.

Commentary: Asymptomatic carotid artery stenosis (unlike symptomatic carotid artery stenosis) is a relatively low-risk condition, and this study confirms its natural history. The annual risk of stroke without surgery was about $2 \%$, which is consistent with findings from previous studies; the annual risk of disabling or fatal stroke was only about $1 \%$.

This trial provides evidence that $\mathrm{CE}$ is efficacious for primary stroke prevention, but the absolute benefit is small (annual absolute risk reduction about $1 \%)$. The study's main end point included all stroke types. If one focuses only on prevention of a disabling or fatal carotid territory ischemic stroke (the main indication for $\mathrm{CE}$ ), the absolute benefit derived from surgery is even smaller. For every 100 patients operated on, about 7 carotid territory strokes (but only 3 disabling or fatal carotid territory ischemic strokes) would be prevented at 5 years and 3 additional strokes or deaths would be caused as a perioperative complication. With advances in medical management, including aggressive reduction of risk factors and more widespread use of preventive treatments, the benefit of surgery may be further narrowed.

The patients in this trial faced an extremely low surgical morbidity and mortality that is difficult to achieve outside of a clinical trial. Because complication rates of $\mathrm{CE}$ are inversely proportional to both hospital and surgeon case volumes, the procedure should not be performed in asymptomatic patients in centres with low case volumes or where the perioperative stroke and death rate exceeds $3 \%$. Independent audits of perioperative complication rates should be made readily available to referring physicians and patients contemplating this procedure. Furthermore, caution is urged when surgical decisions are based solely on carotid ultrasonography, which may misclas- 
sify the degree of stenosis. Newer techniques to identify "high-risk" carotid plaques (e.g., transcranial Doppler emboli detection, magnetic resonance direct thrombus imaging, 3dimensional ultrasonography) are under investigation.

Practice implications: When faced with an individual patient, the decision to opt for surgical management of asymptomatic carotid artery disease is not straightforward (see reference 3 for a comprehensive review). CE should be considered only for carefully selected patients with carotid artery stenosis of at least $60 \%$ who are less than 75 years old, have a good life expectancy and are at low surgical risk. Evidence of subclinical infarcts on brain imaging should be sought, as this may identify patients who actually have symptomatic carotid artery disease even though the symptoms are unrecognized clinically. Improved risk stratification methods are still needed to identify patients who will benefit most from $\mathrm{CE}$ and those who may be most harmed. On the basis of previous reports, patients with a higher degree of carotid artery stenosis, plaque ulceration or subclinical infarcts on brain imaging may be at increased risk of stroke and therefore may benefit more from CE; those with contralateral carotid artery occlusion, atrial fibrillation, congestive heart failure and diabetes may have a higher risk of perioperative stroke or death.

Conservative patients and their physicians will opt for medical management with aggressive reduction of risk factors and antiplatelet, antihypertensive and statin therapies (for plaque stabilization or perhaps plaque regression), although CE for asymptomatic carotid artery stenosis is now a more valid alternative. Asymptomatic carotid artery disease is a marker for coronary artery disease and peripheral vascular disease, which may also require attention. All patients should be educated about symptom recognition and monitored for the development of cerebral or retinal TIA or stroke, which would then indicate urgent referral for CE. Ultimately, patients who will benefit most from CE are those with recent stroke symptoms, and improved efforts directed at recognizing and referring these patients must remain top priority.

\section{David J. Gladstone}

Demetrios J. Sahlas

Division of Neurology

Regional Stroke Centre

Sunnybrook and Women's College

Health Sciences Centre

University of Toronto

Toronto, Ont.

\section{References}

1. Barnett HJM, Meldrum HE, Eliasziw M; for the North American Symptomatic Carotid Endarrterectomy Trial (NASCET) Collaborators. The appropriate use of carotid endarterectomy. CMA7 2002;166(9):1169-79.

2. Perry JR, Szalai JP, Norris JW; Canadian Stroke Consortium. Consensus against both endarterectomy and routine screening for asymptomatic carotid artery stenosis. Arch Neurol 1997; 54(1):25-8.

3. Dodick DW, Meissner I, Meyer FB, Cloft HJ. Evaluation and management of asymptomatic carotid artery stenosis. Mayo Clin Proc 2004;79(7): 937-44.

\section{Books Received}

Campen RB. Blueprints: dermatology. Malden (MA): Blackwell; 2004. 175 pp. US\$28.95 ISBN 1-4051-0441-4

Furlong DJ. Medicare myths: 50 myths we've endured about the Canadian health care system. Saint John (NB): Dreamcatcher; 2004.156 pp. $\$ 24.95$ ISBN 1-894372-39-5

Gill GV, Beeching NJ. Tropical medicine, 5 th ed. Malden (MA): Blackwell; 2004. 352 pp. US\$39.95 ISBN 0-632-06496-X

Heaman EA. St. Mary's: the history of a London teaching hospital. Montreal/Kingston: McGill-Queen's University Press; 2003.519 pp. $\$ 65.00$ (cloth) ISBN 0-7735-2513-0

Kahan S, Smith EG. In a page: signs and symptoms. Malden (MA): Blackwell; 2004. 214 pp. US\$29.95 ISBN 1-4051-0368-X
Low J. Using alternative therapies: a qualitative analysis. Toronto: Canadian Scholars' Press; 2004. 160 pp. S24.95 ISBN 1-55130-264-0

Marbas LL, Case E. Blueprints: clinical procedures. Malden (MA): Blackwell; 2004. 227 pp. US\$39.95 ISBN 1-4051-0388-4

Merletti R, Parker P, editors. Electromyography: physiology, engineering, and noninvasive applications. Hoboken (NJ): John Wiley and Sons; 2004. 494 pp. US\$99.95 ISBN 0-471-67580-6

McLintock L. Smoke-free: how one city successfully banned smoking in all indoor public places. Vancouver (BC): Granville Island; 2004. 216 pp. \$19.95 ISBN 1-894694-31-7

O'Connell JJ, Swain SE, LoeberDaniels C, Strupp-Allen J, editors. The health care of homeless persons: a manual of communicable diseases and common problems in shelters and on the streets. Boston (MA): Guthrie Nixon Smith Printers; 2004. 345 pp. US\$15.00 ISBN 09711650-8-4

McPhedran M, Sutton W. Preventing sexual abuse of patients: a legal guide for health care professionals. Markham (ON): LexixNexis Canada; 2004. 336 pp. \$60.00 ISBN 0-433-441941

Paquette L. Bioterroisum in medical and healthcare administration. New York: Marcel Dekker; 2004. 188 pp. US\$185.00 ISBN 1-4051-1960-8

van Belle G, Fisher LD, Heagerty PJ, Lumley T. Biostatistics: a methodology for the health sciences, 2nd ed. Hoboken (NJ): John Wiley and Sons; 2004. 871 pp. US\$110.00 ISBN 0-471-03185-2 